\title{
The Assessment of Different Combination Prosthetic Repair Techniques and Prognostic Criteria for Early Wound Complications in Median Incisional Ventral Hernias
}

DOI: 10.17691/stm2015.7.2.14

Received April 25, 2014

R.V. Golovin, Surgeon';

N.A. Nikitin, MD, DSc, Professor, Head of the Department of Departmental Surgery²

${ }^{1}$ Northern City Clinical Hospital, 4 Sverdlov St., Kirov, 610011, Russian Federation; ${ }^{2}$ Kirov State Medical Academy, 112 Karl Marx St., Kirov, 610027, Russian Federation

The aim of the investigation was to compare the results of using different techniques of combined prosthetic repair in median incisional ventral hernias, and develop the assessment criteria for the risk of postsurgical wound complications.

Materials and Methods. We studied the effect of four combination prosthetic repair techniques in 152 patients with median incisional ventral hernias W2, W3 and W4: two restorative techniques — onlay $(n=38)$ and sublay $(n=17)$, a reconstructive Belokonev-I technique $(n=49)$ and a reparative technique suggested by the authors $(n=48)$. To determine risk factors of postsurgical wound complications we used a multiple correlation analysis.

Results. There were no fatal cases. Long-term wound exudation was found in 19 of 38 patients $(50 \%)$ after onlay technique, and in 12 of $49(24.5 \%)$ - after Belokonev-l technique. The same groups of patients were observed to develop seromas - $12(31.6 \%)$ and $2(4.1 \%)$ cases respectively. The best life quality levels were found in patients after sublay technique (it was used in W2 hernias only), the lowest — after onlay technique. The life quality levels after Belokonev-I repair and the authors' technique had no significant differences; they were comparable to sublay technique. The developed method for risk assessment of postoperative wound complications enables a surgeon to assess adequately the risk level and deal with controllable prognostic factors, namely endoprosthesis type and alloplasty technique.

Conclusion. Combination prosthetic repair by restorative techniques is inappropriate for median incisional ventral hernias W3-W4 since it causes intra-abdominal pressure increase. An adequate choice of prosthesis type and plasty technique reduces the risk of wound complications.

Key words: incisional ventral hernias; combined prosthetic repair.

Incisional ventral hernias (IVH) develop in 4-15\% patients after laparotomy, and rank next to inguinal hernias. Most frequently IVH occur after urgent surgeries, among IVH median hernias prevailing [1, 2].

In recent three decades synthetic prosthetic repair is a promising direction in IVH treatment [3-5]. And now there is the necessity for a very thoughtful analysis of the experience gained [6]. The most urgent problems now are those related to the need of individual approach to prosthetic repair (PR) selection, the development of novel techniques, intensive study of short- and long-term results, and the prognosis of early wound complications [7-9].

The aim of the investigation was to compare the results of using different techniques of combined prosthetic repair in median incisional ventral hernias, and develop the assessment criteria for the risk of postsurgical wound complications.

Materials and Methods. The study was based on the analysis of the findings and treatment results of 152 patients with median W2, W3 and W4 IVH, who had undergone combined PR. 99 patients had planned surgeries (65.1\%), 53 (34.9\%) - urgent surgeries. There were 58 males and 94 females. Mean age of patients was $58.4 \pm 9.8$ years. W2 hernias were found in 81 patients $(53.3 \%)$, W3 - in $40(26.3 \%)$, W 4 - in $31(20.4 \%)$. It should be noted that 10 patients $(6.6 \%)$ had recurrent hernias, 3 - relapsing hernias. All patients had hernias along median abdominal line; moreover, the proportion of epigastrial and epimesogastric hernias was 59.9\% (91 observations). Among the herniation preceding, biliary tract operations were prevailing - $45.4 \%$ (69 observations). Concomitant diseases in number of from 1 to 5 were revealed in 93 patients $(61.2 \%)$. The most prevailing ones were the following: obesity -88 $(57.9 \%)$, hypertensive disease $-72(47.4 \%)$, coronary heart disease - 33 (21.7\%), bronchopulmonary diseases - 30 (19.7\%).

In the study we used IVH classification according to Chevrel and Rath [10], as well as intra-abdominal hypertension (IAH) classification by Burch et al. [11]. For patients' examination we used clinical and anamnestic, laboratory, electrocardiographic, ultrasonic techniques, and intra-abdominal pressure (IAP) monitoring by Kron

For contacts: Golovin Roman Victorovich, e-mail: gromanson@mail.ru 
et al. [12]. If indicated, we used radiological, endoscopic methods and spirography. Patients' quality of life was assessed using SF-36 questionnaire (Ware, 1992), which is a universal uniform procedure applied in clinical practice and research works.

A total of four techniques of combination PR were used, among them there were two restorative techniques: 38 onlay and 17 sublay observations, a reconstructive Belokonev-I technique - 49 observations, and a reparative technique suggested by the authors -48 observations.

The study complies with the declaration of Helsinki (adopted in June, 1964 (Helsinki, Finland) and revised in October, 2000 (Edinburg, Scotland)) and was approved by local Ethics Committee. All patients were informed of IVH surgery types, the peculiarities of a postoperative period, possible complications, and gave their written informed consent to surgery and data analysis.

The essence of the authors' technique is in the following [13]. Herniotomy is followed by a lengthwise incision of the anterior walls of rectus sheath of hernia orifice full-length by leaving $1 / 2$ of orifice width from the edge (Figure 1). The resulted medial flaps of aponeurosis without separation from muscles are sutured along the lines situated $1.5-2.0 \mathrm{~cm}$ away from flap margins (Figure 2). A graft is stitched in aponeurotic diastases above the abdominal rectus muscle, with graft adjunctive fixation to a median line (Figure 3).

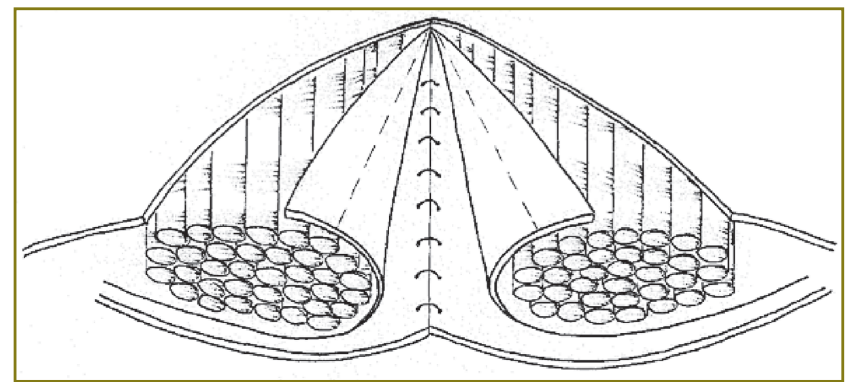

Figure 1. The first stage of prosthetic repair using the authors' technique: incision of the anterior walls of rectus sheath of hernia orifice full-length by leaving $1 / 2$ of orifice width from the edge
The technique excludes the necessity to unwrap medial leaves of aponeurotic flaps, provides the perimeter increase of posterior walls of rectus sheath, maintains stability of rectus muscles along the medial contour, corrects their lateralization and reconstructs an abdominal raphe. Double contour of a graft sutured in, and its fixation to the median line provide effective strengthening of an abdominal wall.

As a meshed graft we used Prolene and Ultrapro meshes (Johnson \& Johnson, USA) and suture material Prolene. The patients were operated on under general anesthesia. When selecting PR type we took into consideration the width of hernia orifices (W criterion), an initial IAP level, and its value after test hernia orifice contracture, the intensity of muscular aponeurotic structure atrophy, the presence of cardiopulmonary comorbidity. Table 1 shows the distribution of patients by urgency of operations, the size of hernia orifices, and a combination PR type. All digital data were statistically processed using Statistica 6.0 software. The reliability of mean values was assessed using Student's coefficient, and the accuracy of percentages of two samplings - by Fisher's ratio test. P-values $<0.05$ were considered significant. A correlation coefficient for parametric criteria was calculated as Pearson correlation coefficient, for nonparametric criteria we used Spearman rank correlation analysis. The accuracy degree of a correlation coefficient was statistically analyzed by

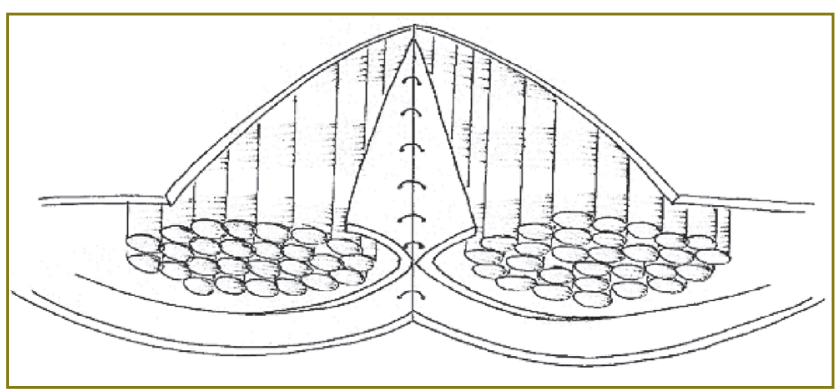

Figure 2. The second stage of prosthetic repair using the authors' technique: suturing of medial flaps of aponeurosis along the lines situated $1.5-2.0 \mathrm{~cm}$ away from flap margins

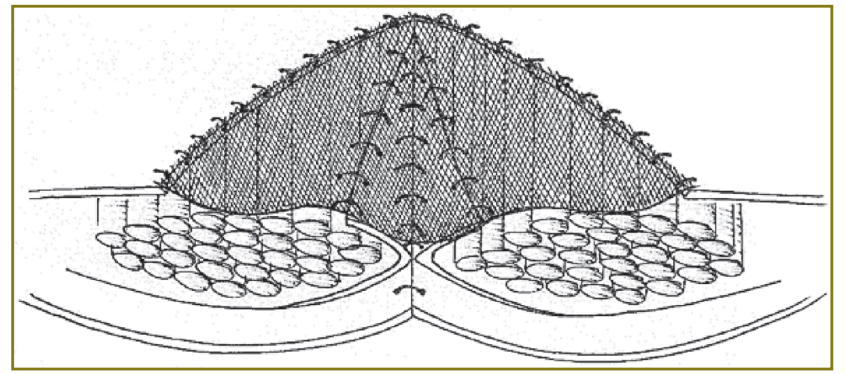

Figure 3. The third stage of prosthetic repair using the authors' technique: a graft is sutured in aponeurotic diastases, with graft adjunctive fixation to a median line 
the tables of critical values for the given significance values $(0.05$ or $0.01)$. The data were considered significant if $p \leqslant 0.05$.

Results and Discussion. Initial IAP level in planned surgery patients (Table 2) significantly grew with $\mathrm{W}$ criterion increase $(p<0.05)$, though did not achieve the threshold level of stage I IAH (12-15 mm Hg). After closing of hernia orifices in W2 hernias, IAP level slightly increased compared to the initial level, but the difference was insignificant $(p>0.05)$. In W3 hernias the closing of hernia orifices was accompanied by significant IAP growth up to the threshold level of stage I IAH $(p<0.05)$, in W4 hernias IAP after closing of hernia orifices appeared to be significantly higher compared to W3 hernias reaching the final values of stage I IAH range $(p<0.05)$.

In urgent patients (Table 3) the initial IAP level was significantly higher compared to planned patients, and grew with $W$ criterion increase $(p<0.05)$. In W2 hernias IAP level did not reached the threshold values of stage I $\mathrm{IAH}$, while in $\mathrm{W} 3$ and $\mathrm{W} 4$ hernias it was within the range of stage I IAH values. After closing of hernia orifices in W2 hernias IAP level increased compared to its initial level reaching in some cases a threshold level of stage I IAH, though the difference was insignificant $(p>0.05)$. In W3

Table 1
Distribution of patients by the urgency of surgery, hernia orifices width, and the type of combination prosthetic repair

\begin{tabular}{|c|c|c|c|c|c|c|}
\hline \multirow[b]{2}{*}{ Surgery type } & \multirow{2}{*}{$\begin{array}{c}\text { Hernia } \\
\text { orifice } \\
\text { width }\end{array}$} & \multicolumn{4}{|c|}{ Combined prosthetic repair type } & \multirow[b]{2}{*}{ Total } \\
\hline & & $\begin{array}{c}\text { Onlay } \\
\text { technology }\end{array}$ & $\begin{array}{c}\text { Sublay } \\
\text { technology }\end{array}$ & $\begin{array}{l}\text { Belokonev-I } \\
\text { technique }\end{array}$ & $\begin{array}{l}\text { Authors' } \\
\text { technique }\end{array}$ & \\
\hline \multirow{3}{*}{ Planned } & W2 & 12 & 12 & 12 & 16 & 52 \\
\hline & W3 & 8 & - & 9 & 9 & 26 \\
\hline & W4 & 4 & - & 9 & 8 & 21 \\
\hline Total planned surgeries & & 24 & 12 & 30 & 33 & 99 \\
\hline \multirow{3}{*}{ Urgent } & W2 & 7 & 5 & 9 & 8 & 29 \\
\hline & W3 & 5 & - & 5 & 4 & 14 \\
\hline & W4 & 2 & - & 5 & 3 & 10 \\
\hline Total urgent surgeries & & 14 & 5 & 19 & 15 & 53 \\
\hline Total & & 38 & 17 & 49 & 48 & 152 \\
\hline
\end{tabular}

hernias the closing of hernia orifices was accompanied by IAP growth up to stage I IAH, while in W4 hernias up to stage II IAH $(16-20 \mathrm{~mm} \mathrm{Hg})(p<0.05)$.

Relying on the findings we performed restorative PR according to onlay technique in 13 patients with W3 hernias (8 planned and 5 urgent patients) and in 6 patients with W4 hernias (4 planned and 2urgent patients) with marked atrophy of muscular aponeurotic structures, and no cardiopulmonary comorbidities. However, a postoperative IAP monitoring showed that after the termination of muscle relaxant action and postanesthetic recovery, IAP in these patients rose sharply. In W3 hernias on day 1 IAP level reached its

Table 2

Dynamics of intra-abdominal pressure $(\mathrm{mm} \mathrm{Hg})$ resulted from different prosthetic repair types in elective patients $(\mathrm{M} \pm \mathrm{m})$

\begin{tabular}{lccccccccccccc}
\hline \multirow{1}{*}{ IAP } & \multicolumn{3}{c}{ Onlay technology } & \multicolumn{3}{c}{ Sublay technology } & \multicolumn{3}{c}{ Belokonev-I technique } & \multicolumn{3}{c}{ Authors' technique } \\
\cline { 2 - 14 } & W2 & W3 & W4 & W2 & W3 & W4 & W2 & W3 & W4 & W2 & W3 & W4 \\
Initial & $7.8 \pm 0.5$ & $9.3 \pm 2.2$ & $10.7 \pm 3.2$ & $6.9 \pm 0.4$ & - & - & $8.3 \pm 1.2$ & $10.1 \pm 0.8$ & $10.6 \pm 1.5$ & $7.8 \pm 0.5$ & $10.3 \pm 1.3$ & $10.8 \pm 1.3$ \\
\hline $\begin{array}{l}\text { After hernia } \\
\text { orifices closing }\end{array}$ & $8.3 \pm 1.1$ & $11.8 \pm 1.6$ & $13.5 \pm 1.2$ & $7.5 \pm 0.6$ & - & - & $8.5 \pm 0.8$ & $12.8 \pm 1.9$ & $14.7 \pm 1.7$ & $8.1 \pm 0.3$ & $12.8 \pm 0.8$ & $14.2 \pm 1.5$ \\
\hline On day 1 & $8.6 \pm 0.8$ & $15.2 \pm 1.5$ & $16.7 \pm 4.2$ & $7.8 \pm 0.2$ & - & - & $8.8 \pm 0.9$ & $11.4 \pm 2.1$ & $13.3 \pm 2.7$ & $7.9 \pm 0.8$ & $11.3 \pm 1.1$ & $12.5 \pm 1.8$ \\
\hline On day 3 & $8.5 \pm 1.3$ & $14.8 \pm 1.8$ & $14.6 \pm 2.8$ & $7.4 \pm 0.3$ & - & - & $8.5 \pm 0.9$ & $11.0 \pm 0.7$ & $11.2 \pm 2.1$ & $7.8 \pm 0.2$ & $10.3 \pm 1.9$ & $10.6 \pm 0.9$ \\
\hline
\end{tabular}

Table 3

Dynamics of intra-abdominal pressure $(\mathrm{mm} \mathrm{Hg})$ resulted from different prosthetic repair types in urgent patients $(\mathrm{M} \pm \mathrm{m})$

\begin{tabular}{lcccccccccccccc}
\hline \multicolumn{1}{c}{ IAP } & \multicolumn{3}{c}{ Onlay technology } & \multicolumn{3}{c}{ Sublay technology } & \multicolumn{3}{c}{ Belokonev-I technique } & \multicolumn{3}{c}{ Authors' technique } \\
& & W2 & W3 & W4 & W2 & W3 & W4 & W2 & W3 & W4 & W2 & W3 & W4 \\
Initial & $11.1 \pm 2.2$ & $12.1 \pm 1.2$ & $14.4 \pm 0.7$ & $10.2 \pm 0.3$ & - & - & $10.5 \pm 0.3$ & $13.5 \pm 1.4$ & $14.9 \pm 1.2$ & $9.8 \pm 0.8$ & $12.5 \pm 2.3$ & $13.9 \pm 0.8$ \\
\hline $\begin{array}{l}\text { After hernia } \\
\text { orifices closing }\end{array}$ & $12.5 \pm 0.7$ & $13.4 \pm 0.5$ & $15.5 \pm 0.6$ & $11.5 \pm 0.7$ & - & - & $10.9 \pm 0.7$ & $15.1 \pm 1.5$ & $17.1 \pm 0.8$ & $10.3 \pm 1.1$ & $14.9 \pm 0.8$ & $16.6 \pm 0.9$ \\
\hline On day 1 & $13.3 \pm 1.7$ & $16.3 \pm 0.8$ & $21.4 \pm 0.8$ & $12.2 \pm 0.2$ & - & - & $11.3 \pm 0.5$ & $14.8 \pm 2.3$ & $16.3 \pm 1.2$ & $10.8 \pm 1.2$ & $13.3 \pm 1.9$ & $16.8 \pm 1.7$ \\
\hline On day 3 & $10.6 \pm 0.8$ & $15.1 \pm 0.9$ & $17.5 \pm 1.6$ & $10.8 \pm 0.3$ & - & - & $10.9 \pm 0.4$ & $13.9 \pm 0.7$ & $15.7 \pm 0.8$ & $10.3 \pm 0.7$ & $12.2 \pm 1.6$ & $14.1 \pm 1.2$ \\
\hline
\end{tabular}


breakpoint, between stages I and II IAH, on day 3 it was within the range of stage I IAH in both planned and urgent patients $(p<0.05)$. In elective patients with W4 hernias on day 1 IAP increased up to stage II, in urgent patients - up to stage III $(20-25 \mathrm{~mm} \mathrm{Hg})$, and on day 3 it corresponded stages I and II IAH $(p<0.05)$. And only in W2 hernia patients regardless the repair type on day 1 IAP level did not differ significantly from that after closing of hernia orifices ( $p>0.05)$, and on day 3 it was near the initial level in both elective and urgent patients.

A different situation arose with postoperative IAP values in W3 and W4 hernia patients after PR according to Belokonev-I technique and a technique suggested by the authors. After closing of hernia orifices, as has been mentioned above, IAP significantly increased, but on the first postoperative day it decreased, and reached its initial level on day $3(p<0.05)$.

The analysis of perioperative IAP monitoring results showed that when choosing a restorative PR type in W3 and W4 hernias it is unreasonable to rely on IAP indices after hernia orifice closure, since these indices are significantly lower than postoperative ones due to complete muscle relaxation of a patient under anesthesia. IAP monitoring showed that in W3 and W4 hernias it was a restorative tension PR. Moreover, the monitoring data enable to select reasonably the technique suggested by the authors, as well as Belokonev-I technique as tension-free techniques.

Thus, it is our opinion that, when selecting PR type, one should take into account the following three main factors: the width of hernia orifices (W criterion), the atrophy intensity of muscular aponeurotic structures, the presence of cardiopulmonary comorbidities, and refuse completely to use restorative techniques in W3 and W4 hernias, except the cases with W2 hernias. It is common knowledge that cardiopulmonary diseases or their presentations in past history, as well as low respiratory function in W2 hernias are contradictions to restorative PR. In such cases reconstructive or reconstructive restorative $\mathrm{PR}$ is indicated, just as in W3 and W4 hernias.
In our study the intensity of muscular aponeurotic atrophy was assessed visually and by palpation. In restorative PR we took atrophy intensity into consideration when choosing the graft placement technology. In marked aponeurosis thinning, and its tendency to dissociation we applied onlay technology, in case there were no marked atrophic changes we gave preference to sublay technology. In reconstructive or reconstructive restorative PR the intensity of tissue (primarily, rectus muscle tissue) atrophy had an impact on the choice of repair type - we had to take into account the recovery rate of abdominal wall anatomy. In case of marked changes we gave preference to reconstructive repair by Belokonev-I, if there were no changes - we applied reconstructive restorative PR using the authors' technique.

There were no lethal cases among the patients. An early postoperative period was assessed by wound exudation duration, drain removal time, the development of wound complications, and the length of hospital stay (Table 4).

We used PR according to sublay technology only in W2 hernias without paraprosthetic space draining, other cases required draining. After PR according to the suggested method, wound discharge, drain removal time and the length of hospital stay were significantly lower than after Belokonev-l technique and onlay technology $(p<0.05)$. Long wound exudation as a complication was found in 19 of 38 patients (50\%) after PR according to onlay technology, and in 12 of 49 patients $(24.5 \%)$ according to Belokonev-I technique, while there was no long wound exudation after the suggested repair technique. Seromas also developed in these groups, in $12(31.6 \%)$ and $2(4.1 \%)$ patients respectively. All cases of seromas required repeated centesis of anterior abdominal wall followed by the content evacuation, prolonged banding, physiotherapy administration, and in three cases after PR according to onlay technology repeated vacuum draining. A wound abscess developed in 2 patients also after PR according to onlay technology, and required antibiotic therapy and surgical treatment of wound.

Table 4

The course of wound complications of postoperative period after prosthetic repair $(\mathrm{M} \pm \mathrm{m})$

\begin{tabular}{lcccc}
\hline \multicolumn{1}{c}{ Parameter } & $\begin{array}{c}\text { Onlay } \\
\text { technology } \\
(\mathbf{n = 3 8 )}\end{array}$ & $\begin{array}{c}\text { Sublay } \\
\text { technology } \\
(\mathbf{n = 1 7 )}\end{array}$ & $\begin{array}{c}\text { Belokonev-I } \\
\text { technique } \\
(\mathbf{n = 4 9 )}\end{array}$ & $\begin{array}{c}\text { Authors' } \\
\text { technique } \\
(\mathbf{n = 4 8})\end{array}$ \\
\hline Average wound discharge per day $(\mathrm{ml})$ & $98.5 \pm 3.2$ & - & $75.4 \pm 1.6$ & $51.2 \pm 1.3$ \\
\hline Average drain removal time (days) & $14.1 \pm 0.3$ & - & $9.8 \pm 1.7$ & $5.4 \pm 0.6$ \\
\hline Long wound exudation (absolute number/\%) & $19 / 50.0$ & - & $12 / 24.5$ & - \\
\hline Seroma (absolute number/\%) & $12 / 31.6$ & - & $2 / 4.1$ & - \\
\hline Pus formation (absolute number/\%) & $2 / 5.3$ & - & - & - \\
\hline Length of hospital stay (days) & $18.7 \pm 2.3$ & $10.2 \pm 1.6$ & $17.2 \pm 1.3$ & $13.2 \pm 0.4$ \\
\hline
\end{tabular}


After discharge from hospital, temporal disability in patients after onlay technology was $36.0 \pm 3.2$ days, after sublay repair $-25.4 \pm 2.5$ days, after Belokonev-I techniques and the authors' method $-32.2 \pm 1.2$ days. The shorter periods of temporary disability in patients after sublay technology are due to the fact that this technique is used in W2 hernias only, and results in no wound complications.

We studied long-term results and the quality of life according to SF-36 questionnaire in 148 patients $(97.3 \%)$ over the period of $1-3$ years (Table 5). The patients after sublay technique appeared to have the highest life quality parameters. The lowest indices were observed in patients after hernia repair according to onlay technology. Life quality indicators of patients after PR according to Belokonev-I technique and a novel technique had no significant difference $(p>0.05)$. These techniques had no significant differences with sublay technology in life quality parameters as well $(p>0.05)$. They significantly differed from onlay technology, both in general, and in some parameters $(\mathrm{p}<0.05)$.

Muscular tissue, in contrast to aponeurosis, is known to have high resorptive characteristics. The more the prosthesis-muscle contact surface, the more pronounced exudate resorption processes [14, 15]. Reasoning from this fact, we measured general wound surface area $\left(S_{w}\right)$ and exposed muscle area $\left(S_{m}\right)$ in PR according to Belokonev-I technique (35 observations) and according a new technique (41 observations). The area ratio was taken as a resorptive activity coefficient (K). During onlay technique muscular structures are not exposed, and a graft contacts with aponeurotic tissue only, $\mathrm{K}$ always being equal to 0 . In PR according to sublay technology a graft is placed subor retromuscularly, and all its surface contacts with muscular tissue, $K$ being equal to 1 . In Belokonev-I technique $\mathrm{K}$ was $0.35 \pm 0.027$ (the range from 0.26 to 0.43 ), when a novel technique was used $\mathrm{K}$ was $0.73 \pm 0.016$ (the range from 0.68 to 0.83 ). The coefficient value enables to assess the preventive significance of a technique used with relation to possible development of long wound exudation and seromas.

To establish reliable and available risk criteria of developing long wound exudation and seromas, we carried out a multiple

Table 5

Table 6 correlation analysis of indices in a patient group, and developed scoring of complication risk prognosis [16]. Each patient was assessed by 17 parameters. According to the calculation data: if a correlation coefficient was from 0.6 to 0.9 , the relation between the compared parameters was strong, if a coefficient was lower or negative - the relation was weak, in a zero correlation coefficient - impossible.

The relationship between the following six factors appeared to be significant: hernia duration, hernia orifice width (W criterion), endoprosthetic area, endoprosthetic type (density), PR technique, resorptive activity coefficient value (K). To develop a score assessment system of the risk of developing long wound exudation and seromas, each sign was assigned a score ranging from 1 to 3 due to its intensity (Table 6).

Among 81 patients with scores in the range from 6 to $10(\mathrm{M} \pm \mathrm{m}-9.3 \pm 0.4)$ none wound complications were found. Long wound exudation developed in 31 (54.4\%) of 57 patients with scores from 11 to $14(\mathrm{M} \pm \mathrm{m}-$ $13.8 \pm 0.9$ ). All 14 patients with scores ranging from 15 to $18(\mathrm{M} \pm \mathrm{m}-16.5 \pm 1.2)$ were recorded to have seromas. Therefore, the values in the range from 6 to 10 scores should be interpreted as a low risk interval; from 11 to

Quality of life in patients with incisional ventral hernias after combination prosthetic repair plasty (SF-36 questionnaire) $(\mathrm{M} \pm \mathrm{m})$

\begin{tabular}{lcccc}
\hline SF-36 Questionnaire criteria & \multicolumn{4}{c}{ Combination prosthetic repair type } \\
\cline { 2 - 5 } & $\begin{array}{c}\text { Onlay } \\
\text { technology } \\
(\mathbf{n}=\mathbf{3 8})\end{array}$ & $\begin{array}{c}\text { Sublay } \\
\text { technology } \\
(\mathbf{n}=\mathbf{1 5})\end{array}$ & $\begin{array}{c}\text { Belokonev-I } \\
\text { technique } \\
(\mathbf{n}=\mathbf{4 8})\end{array}$ & $\begin{array}{c}\text { Authors' } \\
\text { technique } \\
(\mathbf{n}=\mathbf{4 7})\end{array}$ \\
\hline Physical functioning (PF) & $58.3 \pm 3.7$ & $83.1 \pm 6.3$ & $69.5 \pm 5.2$ & $75.8 \pm 2.2$ \\
\hline Role-physical functioning (RP) & $62.1 \pm 1.2$ & $69.4 \pm 2.5$ & $68.4 \pm 7.2$ & $72.3 \pm 5.1$ \\
\hline Bodily pain (BP) & $53.2 \pm 2.1$ & $91.3 \pm 3.4$ & $84.3 \pm 6.8$ & $88.3 \pm 1.5$ \\
\hline General health (GH) & $61.8 \pm 4.7$ & $69.6 \pm 1.8$ & $66.0 \pm 5.7$ & $69.1 \pm 4.3$ \\
\hline Vitality (VT) & $52.3 \pm 1.3$ & $76.8 \pm 4.3$ & $70.1 \pm 5.3$ & $75.3 \pm 1.8$ \\
\hline Social functioning (SF) & $62.3 \pm 1.2$ & $79.2 \pm 3.4$ & $67.2 \pm 7.9$ & $70.2 \pm 5.3$ \\
\hline Role-emotional (RE) & $54.1 \pm 1.5$ & $69.5 \pm 1.2$ & $68.3 \pm 6.8$ & $75.1 \pm 1.4$ \\
\hline Mental health (MH) & $55.7 \pm 1.3$ & $78.6 \pm 4.5$ & $69.5 \pm 3.2$ & $69.3 \pm 1.5$ \\
\hline
\end{tabular}

Risk assessment of developing long wound exudation and seromas in patients with incisional ventral hernias after combination prosthetic repair plasty

\begin{tabular}{lcccc}
\hline \multicolumn{1}{c}{ Factor } & $\begin{array}{c}\text { Correlation } \\
\text { coefficient }\end{array}$ & $\mathbf{1}$ & $\mathbf{2}$ & $\mathbf{3}$ \\
\hline Hernia duration & 0.65 & $\begin{array}{c}\text { Under } \\
5 \text { years }\end{array}$ & $>5$ years & $\begin{array}{c}>5 \text { years + } \\
\text { recurrence }\end{array}$ \\
\hline Width of hernia orifices (W) & 0.73 & W2 & W3 & W4 \\
\hline Implant type (density) & $0.71 \mathrm{~g} / \mathrm{m}^{2}$ & $30-70 \mathrm{~g} / \mathrm{m}^{2}$ & $70-100 \mathrm{~g} / \mathrm{m}^{2}$ & $\geqslant 100 \mathrm{~g} / \mathrm{m}^{2}$ \\
\hline Endoprosthesis area & $0.61 \mathrm{~cm}^{2}$ & About $225 \mathrm{~cm}^{2}$ & $225-400 \mathrm{~cm}^{2}$ & $\geqslant 400 \mathrm{~cm}^{2}$ \\
\hline Repair technique & 0.9 & Sublay & Tension-free & Onlay \\
\hline Resorption activity coefficient (K) & 0.85 & $0.6-1.0$ & $0.3-0.6$ & $0-0.3$ \\
\hline
\end{tabular}


14 - a moderate risk interval; from 15 to 18 - a high risk interval for developing long wound exudation and seromas.

The suggested score system to assess the risk of developing long wound exudation and seromas in patients with IVH let a surgeon deal with 3 of 6 factors: endoprosthesis type, PR technique, and a resorptive activity coefficient $(\mathrm{K})$ related to $\mathrm{PR}$ type. Adequate selection of prosthetic material and PR technique increasing a resorptive activity coefficient $(K)$ will contribute to the risk reduction of wound complication development.

Conclusion. The selection of a prosthetic repair technique in patients with incisional ventral hernias should be based on the consideration of hernia orifice width (W criterion), atrophy intensity of muscular aponeurotic structures, and the presence of cardiopulmonary pathology. In median hernias W3-W4 a surgeon should refuse combined restorative hernia repair, and there will be no need to monitor perioperative intra-abdominal pressure. These techniques are indicated to patients with W2 hernias only, providing that they have no concurrent cardiopulmonary diseases. Sublay technology is to be a method of choice in such patients. The use of onlay technology is to be limited due to marked atrophic changes of muscular aponeurotic structures. Patients with W2 hernias and concurrent cardiopulmonary diseases, as well as all patients with W3-W4 hernias are indicated combined reconstructive prosthetic repair. The suggested prognostic method of wound complication development enables a surgeon to assess adequately the risk level and intentionally deal with controlled prognosis factors, as follows: endoprosthesis type, repair technique, and a resorptive activity coefficient related to prosthetic repair type.

Study Funding. The study was funded by the authors.

Conflict of Interests. The authors have no conflicts of interest related to the present study.

\section{References}

1. Belokonev V.I., Fedorina T.A., Kovaleva Z.V., Pushkin S.Yu.., Nagapetyan S.V., Supil'nikov A.A. Patogenez i khirurgicheskoe lechenie posleoperatsionnykh ventral'nykh gryzh [Rathogenesis and surgery of incisional ventral hernias]. Samara: GP "Perspektiva"; 2005; 208 p.

2. Tsverov I.A., Bazaev A.V. Surgical treatment of patients with ventral hernias: modern state. Sovremennye tehnologii $v$ medicine 2010: 4: 122-127.

3. Blagovestnov D.A., Upyrev A.V., Srukova A.H. The role and place of prosthesis fitting methods of forward belly wall plasticity in primary median hernia surgery. Vestnik novykh meditsinskikh tekhnologiy 2011; 1(18): 153-155.

4. Ramakrishna H.K., Lakshman K. Intra peritoneal polypropylene mesh and newer meshes in ventral hernia repair: what EBM says? Indian J Surg 2013; 75(5): 346-351, http://dx.doi.org/10.1007/s12262-012-0743-x.

5. Romanov R.V., Fedaev A.A., Petrov V.V., Khodak V.A., Parshikov V.V. The intraperitoneal tension-free plasty of abdominal wall with mesh use - current state of problem. Sovremennye tehnologii v medicine 2012; 4: 161-170.

6. Lyubykh E.N., Polubkova G.V. About some topical problems of herniology and the ways to solve them. Gerniologiya 2009; 2: 14-17.

7. Ermolov A.S., Upyrev A.V., Il'chev V.A. Intraoperative modeling of abdominal wall in incisional abdominal hernias. Gerniologiya 2009; 3(23): 14.

8. Pushkin S.lu., Belokonev V.I. Treatment of medial ventral hernias with the use of synthetic endoprosthesis. Khirurgiya 2010; 6: 43-45.

9. Vlasov A.V. The prediction of the probability of seroma development in case of endoprosthesis replacement of ventral hernias. Sovremennye problemy nauki i obrazovaniya 2013; 2. URL: http://www.science-education.ru/108-8585 (submission date: 28.11.2013).

10. Chevrel J.P., Rath A.M. Classification of incisional hernias of the abdominal wall. Hernia 2000; 4(2): 94, http:// dx.doi.org/10.1007/bf02353754.

11. Burch J.M., Moore E.E., Moore F.A., Francose R. The abdominal compartment syndrome. Surg Clin North Am 1996; 76(4): 838-842, http://dx.doi.org/10.1016/s00396109(05)70483-7.

12. Kron I.L., Harman P.K., Nolan S.P. The measurement of intraabdominal pressure as a criterion for abdominal reexploration. Ann Surg 1984; 199(1): 28-30, http://dx.doi. org/10.1097/00000658-198401000-00005.

13. Nikitin N.A., Zlobin A.I., Golovin R.V. Sposob gernioplastiki pri ventral'nykh gryzhakh sredinnoy lokalizatsii [Hernia repair technique in medial ventral hernias]. Patent RF 2398530. 2010.

14. Arichin N.I., Borisevich G.F. Mikronasosnaya deyatel'nost' skeletnykh myshts pri ikh rastyazhenii [Micropump activity of skeletal muscles in their stretching]. Minsk: Nauka i tekhnika; 1986.

15. Schumpelic V., Klinge U., Junge K., Stumpf M. Incisional abdominal hernia: the open mesh repair. Langenbecks Arch Surg 2004; 389(4): 1-5, http://dx.doi.org/10.1007/s00423-0030352-z.

16. Nikitin N.A., Golovin R.V. Avtomatizirovannaya otsenka stepeni riska razvitiya posleoperatsionnykh oslozhneniy $u$ bol'nykh s posleoperatsionnymi ventral'nymi gryzhami pri ispol'zovanii alloprotezov. Svidetel'stvo o gosudarstvennoy registratsii programmy dlya EVM 2011616534 [Automated risk assessment of postoperative complications in patients with incisional ventral hernias using alloprostheses. State registration certificate for computer program 2011616534]. 2011. 